\title{
Management of adverse events in patients with hormone receptor-positive breast cancer treated with everolimus: observations from a phase III clinical trial
}

\author{
Mary E. Peterson
}

Received: 5 September 2012 / Accepted: 21 April 2013 /Published online: 19 May 2013

(C) The Author(s) 2013. This article is published with open access at Springerlink.com

\begin{abstract}
Everolimus is a mammalian target of rapamycin (mTOR) inhibitor approved for the treatment of advanced renal cell carcinoma, pancreatic neuroendocrine tumors, subependymal giant cell astrocytoma associated with tuberous sclerosis complex, renal angiomyolipoma and tuberous sclerosis complex, and, in combination with exemestane, for hormone receptor-positive HER2-negative advanced breast cancer after failure of treatment with letrozole or anastrozole. Results from the phase III BOLERO-2 trial demonstrated that everolimus in combination with exemestane provided significant clinical benefit to patients with advanced hormone receptor-positive breast cancer. Although everolimus is generally well tolerated, as with most therapies administered in an advanced cancer setting, drugrelated adverse events (AEs) inevitably occur. Most common AEs observed in the everolimus studies include stomatitis, rash, infection, noninfectious pneumonitis, and hyperglycemia. Clinical awareness and early identification of such AEs by oncology nurses are essential to dosing (interruptions, reduction, and treatment discontinuation); quality of life; and, ultimately, patient outcomes. Because everolimus has already been shown to significantly improve clinical efficacy in patients with advanced breast cancer, a proactive approach to the practical management of AEs associated with this mTOR inhibitor as well as other most common AEs observed in this patient population has been reviewed and outlined here.
\end{abstract}

Keywords mTOR inhibitor - Adverse event · Management . Everolimus $\cdot$ Breast cancer $\cdot$ Hormone receptor

M. E. Peterson $(\bowtie)$

Banner MD Anderson Cancer Center, 2940 Banner Gateway

Drive, Suite 400, Gilbert, AZ 85234, USA

e-mail: Mary.Peterson@bannerhealth.com

\section{Introduction}

In 2012, an estimated 229,060 new cases of invasive breast cancer (BC) are expected in the USA, including 2,190 cases occurring in men [1]. For women with hormone receptor (HR)-positive BC (approximately $70 \%$ of patients with $\mathrm{BC}$ ), effective treatment options in the metastatic or locally advanced setting are currently limited [2,3]. Although substantial decreases in incidence were observed between 2002 and 2003 (largely because of reductions in use of hormone replacement therapy), the annual incidence rate since 2003 remains relatively unchanged [4]. Metastatic $\mathrm{BC}$ represents approximately $5 \%$ of all $\mathrm{BC}$ cases [4], and 39,920 BC deaths are expected in 2012 [1]. The use of endocrine therapies in the advanced HR-positive BC setting has significantly improved clinical outcomes in women; however, many patients fail to respond to first-line treatment or experience disease progression after an initial response [5-9]. Consequently, the continuing development of novel therapies for the treatment of advanced HR-positive BC remains of significant importance in the area of oncology.

New therapeutic strategies include the use of targeted agents with varying mechanisms of action. As a class, mammalian target of rapamycin (mTOR) inhibitors exhibit significant clinical antitumor activity in a wide variety of cancer types, including renal cell carcinomas (RCC), mantle cell lymphoma, pancreatic neuroendocrine tumors, metastatic sarcomas, and metastatic BC [10-19]. mTOR forms an important component of the phosphoinositide 3-kinase/Akt signaling pathway that mediates cell growth and proliferation, and dysregulation of this pathway is observed in many cancers, including BC $[20,21]$.

Oral mTOR inhibitor everolimus (Afinitor ${ }^{\circledR}$ ) received approval in 2009 from the US Food and Drug Administration (FDA) for treatment of advanced RCC after failure of 
sorafenib or sunitinib [22]. Everolimus received subsequent approval from the FDA for the treatment of advanced pancreatic neuroendocrine tumors that are unresectable, locally advanced, or metastatic and for the treatment of subependymal giant cell astrocytoma associated with tuberous sclerosis complex in patients who require therapeutic intervention but are not amenable to surgery [22]. In 2012, everolimus was approved by the FDA for the treatment of adults with renal angiomyolipoma and tuberous sclerosis complex not requiring immediate surgery and, in combination with exemestane, for the treatment of advanced HR-positive HER2-negative BC after failure of treatment with letrozole or anastrozole [22]. The European Medicines Agency has also approved everolimus for the management of tumors and conditions described above. Additionally, low-dose everolimus (Zortress ${ }^{\circledR}$ ) in combination with basiliximab and concurrently with reduced doses of cyclosporine and corticosteroids received FDA approval in 2010 for the prevention of organ rejection in kidney transplant recipients [23] and Certican ${ }^{\circledR}$ (worldwide) in combination with cyclosporine was approved in 2003 for the prevention of organ rejection in heart, liver, and kidney transplant recipients [24].

More recently, results from the pivotal phase III Breast Cancer Trials of Oral Everolimus (BOLERO)-2 study demonstrated everolimus in combination with the endocrine agent exemestane significantly extended progression-free survival (PFS) compared with placebo plus exemestane in women with advanced HR-positive, HER2-negative BC $[17,18]$. Patient-centered strategies should be devised to manage the often-inevitable adverse events (AEs) associated with any specific cancer therapy. In this article, safety data and previous clinical experience will be used as a basis to describe $\mathrm{AE}$ management recommendations for patients with $\mathrm{BC}$ who receive everolimus.

\section{BOLERO-2 trial summary}

BOLERO-2 was a phase III, randomized, double-blind, placebo-controlled, multicenter study. conducted at 189 sites worldwide (NCT00863655) [17,18]. A total of 724 patients with postmenopausal advanced HR-positive, HER2-negative $\mathrm{BC}$ refractory to previous letrozole or anastrozole were enrolled and those who met the study criteria were randomly assigned (2:1) to receive oral everolimus $10 \mathrm{mg} /$ day plus oral exemestane $25 \mathrm{mg} /$ day $(n=485)$ or placebo plus oral exemestane $25 \mathrm{mg} /$ day $(n=239)[17,18]$. An interim analysis based upon 7.1 months of follow-up determined that everolimus plus exemestane significantly improved PFS compared with exemestane alone (6.9 vs. 2.8 months, respectively; hazard ratio $=0.43 ; 95 \%$ CI $0.35-0.54, p<0.001$, local assessment) [17]. With 12 months of median follow-up, PFS based on local investigator radiology assessment was 7.4 months for everolimus plus exemestane versus 3.2 months for exemestane only (hazard ratio $=0.44 ; 95 \%$ CI $0.36-0.53 ; p<0.001$ ) [18]. Recently, an 18-month follow-up analysis determined that the median PFS was 7.8 months versus 3.2 months (hazard ratio $=$ 0.45 ; $95 \%$ CI $0.38-0.54, p<0.001$ local assessment) for combination versus exemestane-only therapy, respectively $(p<$ 0.001) [25]. Overall AEs observed in BOLERO-2 at the interim analysis (7.1 months of follow-up) (Table 1) [17] were consistent to $\mathrm{AE}$ rates observed at the 12- and 18-month follow-ups $[18,25]$ as well as with those previously reported with mTOR inhibitors $[10,11]$.

Potential adverse events encountered by the patient

Recognizing the unique AEs associated with anticancer agents allows providers to individualize treatment plans and thereby limit AEs that may decrease a patient's ability to complete a full course of therapy. Oncology professionals involved in the day-to-day care of patients need to accurately recognize AEs associated with specific cancer therapies and incorporate complementary supportive care treatments to monitor, assess, and manage symptoms. Notably, the Oncology Nursing Society (ONS) has played a critical role in evaluating the array of available clinical evidence associated with the treatment of cancer therapy-related AEs. The following discussion of the most commonly observed AEs in the BOLERO-2 study based on the published report [17] and the proposed management strategies is based on the efforts of the ONS, who provided evidence-based management strategies, together with a current review of the literature.

\section{Class-specific adverse events associated with everolimus combination therapy observed in the BOLERO-2 study}

\section{Stomatitis}

Stomatitis, or oral mucositis, refers specifically to inflammatory diseases of the mouth, including mucosa, dentition, periapical abscesses, and periodontium. Such ailments can impair a patient's ability to eat, swallow, and talk and can cause significant pain. Stomatitis is characterized by ulceration in the oroesophageal mucosa, resulting in pain, erythema, dysphagia, and occasionally bleeding $[26,27]$. Onset typically occurs early $(\leq 1$ month after treatment initiation) and is transient $[28,29]$. The condition is also a common toxicity associated with chemotherapy or radiation therapy, occurring as nonspecific ulcerations for which localized palliative treatments and systemic analgesics are generally applied $[28,30]$. In contrast to stomatitis associated with chemotherapy or radiation therapy, stomatitis associated with mTOR therapy has an inflammatory component often clinically mimicking aphthous stomatitis (commonly known as canker sores) and is differentiated from lesions of viral etiology by their localization to the nonkeratinized 
Table 1 Incidence of any-grade AEs occurring in $\geq 30 \%$ or grade 3 or 4 AEs occurring in $\geq 3 \%$ of patients enrolled in BOLERO-2 (interim analysis, 7.1 months of follow-up) [17]

${ }^{a}$ Data on file, Novartis Pharmaceuticals Corporation. Includes all infections and infestations as defined by CTCAE criteria. Note that all other AEs in this table refer to specific preferred terms outlined by CTCAE criteria [47]

\begin{tabular}{|c|c|c|c|c|c|c|}
\hline \multirow[b]{2}{*}{ Preferred term } & \multicolumn{3}{|c|}{$\begin{array}{l}\text { Everolimus + exemestane } \\
(n=482), \%\end{array}$} & \multicolumn{3}{|c|}{$\begin{array}{l}\text { Placebo }+ \text { exemestane } \\
(n=238), \%\end{array}$} \\
\hline & All grades & Grade 3 & Grade 4 & All grades & Grade 3 & Grade 4 \\
\hline Stomatitis & 56 & 8 & 0 & 11 & 1 & 0 \\
\hline Infection $^{\mathrm{a}}$ & 44 & 4 & 2 & 21 & 2 & 0 \\
\hline Rash & 36 & 1 & 0 & 6 & 0 & 0 \\
\hline Fatigue & 33 & 3 & $<1$ & 26 & 1 & 0 \\
\hline Diarrhea & 30 & 2 & $<1$ & 16 & 1 & 0 \\
\hline Dyspnea & 18 & 4 & 0 & 9 & 1 & $<1$ \\
\hline Anemia & 16 & 5 & 1 & 4 & $<1$ & $<1$ \\
\hline $\begin{array}{l}\text { Aspartate aminotransferase } \\
\text { increased }\end{array}$ & 13 & 3 & $<1$ & 6 & 1 & 0 \\
\hline Hyperglycemia & 13 & 4 & $<1$ & 2 & $<1$ & 0 \\
\hline Pneumonitis & 12 & 3 & 0 & 0 & 0 & 0 \\
\hline $\begin{array}{l}\text { Alanine aminotransferase } \\
\text { increased }\end{array}$ & 11 & 3 & $<1$ & 3 & 2 & 0 \\
\hline
\end{tabular}

movable oral and oropharynx mucosa, as opposed to the mucosa of the palate, gingiva, or dorsal tongue surface [28,31]. These differences also suggest that the aphthous-like lesions observed with mTOR inhibitors differ from the lesions observed with cytotoxic agents [28], so management strategies to prevent or treat mTOR inhibitor associated stomatitis also must be distinguished.

\section{Management recommendations}

Because stomatitis is a common AE (Table 1) experienced by patients treated with everolimus [27], prophylactic treatment and early recognition of this AE is highly important. Early and active management includes the promotion of good oral hygiene: consistent, regular, and thorough brushing with a soft toothbrush that is changed on a regular basis; daily flossing; frequent rinsing with bland rinses such as sterile water, normal saline, or sodium bicarbonate; and use of oral moisturizers [27,32].

Based on the clinical trial experience with patients treated with everolimus, various management strategies depending on the grade of stomatitis observed are recommended (Table 2) [22]. The prescribing information for everolimus specifically recommends that rinse formulations that contain alcohol should be avoided [22]. The use of toothpastes that are strong-flavored and that contain sodium lauryl sulfate are not advised; milder, sodium lauryl sulfatefree toothpaste (e.g., children's flavors) should be used instead [28]. Overall, oncology nurses should work to promote an oral program that addresses basic oral needs to help reduce the amount of microbial flora, reduce pain and bleeding, and prevent infection. Patients also should be advised to avoid acidic, spicy, and hard or crunchy foods and to consume foods that are tepid rather than hot in temperature to prevent the potential for mechanical injury [28,30].

Early recognition and immediate effective treatment of stomatitis is essential to reduce the number and severity of ulcers. Although experience in managing everolimusassociated stomatitis is limited, it is recommended that topical corticosteroids and mouthwashes be used, similar to those managed with chemotherapy induced stomatitis [27]. Consistently, standard treatment options include topical high-potency corticosteroids (e.g., dexamethasone, $0.1 \mathrm{mg} / \mathrm{mL}$; clobetasol gel, $0.05 \%$ ), topical nonsteroidal anti-inflammatories (e.g., amlexanox, $5 \%$ oral paste), and topical anesthetics ("miracle" or "magic" mouthwashes typically containing viscous lidocaine, diphenhydramine, and an antacid such as aluminum hydroxide or magnesium hydroxide), and nonimidazole antifungals also may be appropriate for some patients [27,28]. Agents containing hydrogen peroxide, iodine, and thyme derivatives should be avoided in patients with stomatitis [22,27]. L-Lysine $500 \mathrm{mg} /$ day orally, originally used for recurrence of herpes simplex infections, may also be beneficial in patients with recurring oral ulcers [33].

\section{Rash}

Rash induced by treatment with mTOR inhibitors (Table 1) typically occurs as maculopapular or papulopustular lesions, often with pruritus, and erythematous papules or pustules usually constitute the primary lesion morphology [34,35]. Rash primarily occurs on the trunk, scalp, face, and neck, with extremities commonly involved [34,35]. The condition generally appears during the first months of everolimus treatment and is most often grade 1 to 2 in severity [34,35]. 
Table 2 Recommended clinical management strategy: stomatitis [22]

\begin{tabular}{|c|c|c|c|}
\hline Grade & Symptoms & Management & Everolimus dose modification \\
\hline 1 & Minimal (normal diet) & $\begin{array}{l}\text { - Manage with nonalcoholic or salt water }(0.9 \%) \\
\text { mouth wash several times a day }\end{array}$ & - No dose adjustment required \\
\hline 2 & $\begin{array}{l}\text { Symptomatic but can eat } \\
\text { and swallow modified diet }\end{array}$ & $\begin{array}{l}\text { - Manage with topical analgesic mouth } \\
\text { treatments (e.g., benzocaine, butyl } \\
\text { aminobenzoate, tetracaine hydrochloride, } \\
\text { menthol, or phenol) with or without } \\
\text { topical corticosteroids (i.e., triamcinolone } \\
\text { oral paste) } \\
\text { - Avoid agents containing alcohol, } \\
\text { hydrogen peroxide, iodine, and thyme } \\
\text { derivatives }\end{array}$ & $\begin{array}{l}\text { - Temporary dose interruption until } \\
\text { recovery to grade } \leq 1 \\
\text { - Reinitiate everolimus at the same } \\
\text { dose } \\
\text { - If stomatitis recurs at grade } 2 \text {, } \\
\text { interrupt dose until recovery to } \\
\text { grade } \leq 1 \text {. Reinitiate everolimus at a } \\
\text { lower dose }\end{array}$ \\
\hline 3 & $\begin{array}{l}\text { Symptomatic and unable to } \\
\text { adequately eat or hydrate orally }\end{array}$ & & $\begin{array}{l}\text { - Temporary dose interruption until } \\
\text { recovery to grade } \leq 1 \text {. Reinitiate } \\
\text { everolimus at a lower dose }\end{array}$ \\
\hline 4 & Severe (symptoms are life threatening) & & $\begin{array}{l}\text { - Discontinue everolimus and treat } \\
\text { with appropriate medical therapy }\end{array}$ \\
\hline
\end{tabular}

\section{Management recommendations}

Patient awareness and early intervention is important for managing rash. Patients should be informed of the possibility of developing rash and should promptly report the first signs or symptoms in order to initiate early intervention [35]. Patients should also be educated on the need for moisturizing frequently; using a thick, alcohol-free emollient cream such as Eucerin ${ }^{\circledR}$, Aquaphor ${ }^{\circledR}$, or Cetaphil ${ }^{\circledR}$; taking short, lukewarm showers; using mild moisturizing, fragrance-free soap; and bathing in lukewarm water with one to two cups of baking soda or Aveeno ${ }^{\circledR}$ bath treatment added to the water [36]. Patients should also be advised to use a sunscreen of SPF 15 or higher, preferably containing zinc oxide or titanium dioxide, in order to minimize sun exposure [36]. Management strategies when rash develops should be based on clinical phenotype [35]. For grade 1 papulopustular rash, a course of topical low- to moderate-strength corticosteroid and topical antibiotics should be sufficient; for grade 3 or intolerable grade 2 rashes, oral antibiotics for 2 to 4 weeks are advocated. For grade 1 maculopapular rash, topical low- to moderate-strength corticosteroids and oral antihistamines should be considered; for grade 3 or intolerable grade 2 rashes, oral corticosteroids and dose reduction/interruption may be required [35].

\section{Hyperglycemia}

Hyperglycemia is characterized by an abnormally high concentration of glucose in the blood plasma. According to the American Diabetes Association, this is generally a fasting glucose level $>130 \mathrm{mg} / \mathrm{dL}$ or postprandial level $>180 \mathrm{mg} / \mathrm{dL}$ [37]. Symptoms of hyperglycemia include frequent urination, increased thirst, fatigue, blurred vision, weight loss, headaches, and difficulty concentrating. A common toxicity associated with treatment with mTOR inhibitors (Table 1), hyperglycemia is generally well tolerated with a low incidence of treatment discontinuation among patients with cancer $[10,17,38,39]$.

\section{Management recommendations}

Monitoring of fasting serum glucose is recommended before the start of anticancer therapy and periodically thereafter [27]. Optimal glycemic control should be achieved before initiating therapy with an mTOR inhibitor and the patient be made aware of symptoms that may develop. For patients with glucose levels greater than the upper limit of normal (160 mg/dL; grade 1 hyperglycemia), no treatments or dose modifications are recommended [27]. Patients with glucose levels of $>160-250 \mathrm{mg} / \mathrm{dL}$ (grade 2), $>250-500 \mathrm{mg} / \mathrm{dL}$ (grade 3), or $>500 \mathrm{mg} / \mathrm{dL}$ (grade 4) should be treated according to the American Diabetes Association and European Association for the Study of Diabetes consensus algorithm (Fig. 1) [27,40].

As a general strategy, a patient who develops hyperglycemia should be recommended to drink plenty of water, exercise regularly, and reduce dietary amounts of carbohydrates and sugar [37]. In severe cases of hyperglycemia, oral antidiabetics may be administered [37,41].

Noninfectious pneumonitis

Noninfectious pneumonitis is a class effect of mTOR inhibitors (Table 1) characterized by a nonmalignant infiltration of the lungs [42-44]. Current evidence suggests this agentrelated condition may be immunologically mediated $[27,44]$. Nonspecific respiratory signs and symptoms of pneumonitis include cough, dyspnea, hypoxia, and occasionally pleural 


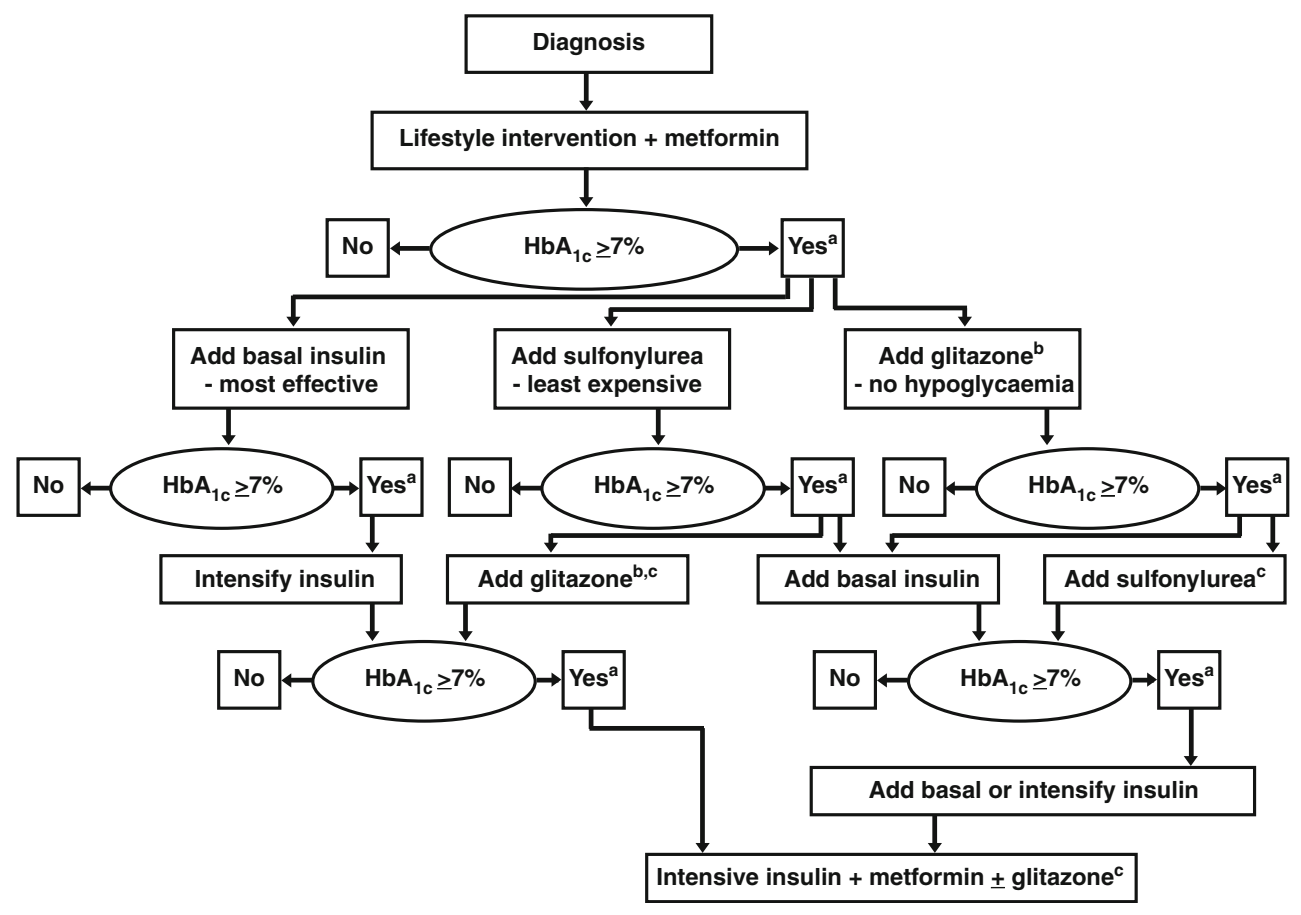

Fig. 1 American Diabetes Association and European Association for the Study of Diabetes consensus approach for the treatment of hyperglycemia [40]. Reinforce lifestyle intervention at every visit. ${ }^{\mathrm{a}} \mathrm{Check} \mathrm{HbA}_{1 \mathrm{c}}$ every 3 months until $\mathrm{HbA}_{1 \mathrm{c}}$ is $<7 \%$, and then at least every 6 months. ${ }^{\mathrm{b}}$ Associated with increased risk of fluid retention, congestive heart failure, and fractures. Rosiglitazone, but probably not pioglitazone, may be associated with an increased risk of myocardial infarction. ${ }^{\mathrm{c}}$ Although

effusion, although some patients remain asymptomatic. Common radiographic changes observed with mTOR inhibitorassociated pneumonitis include ground-glass opacities and focal consolidation, predominantly in the lower lobes [42,44].

\section{Management recommendations}

For patients with respiratory symptoms (cough, dyspnea during exertion or at rest) or with documented multiple lung metastases, a baseline computed tomography scan and pulmonary function tests should be performed before initiation of treatment with everolimus. If predicted single breath transfer factor is $<40 \%$, everolimus therapy should not be initiated until pulmonary function test results have normalized [27]. If no pulmonary compromise exists, baseline computed tomography scans may be obtained at the physician's discretion [27]. The potential diagnosis of noninfectious pneumonitis should also be investigated in patients with nonspecific respiratory signs and symptoms during everolimus treatment. Radiographic imaging should be performed and bronchoalveolar lavage may be useful to rule out infection and evaluate lung inflammation [27]. Therapy should be interrupted and corticosteroid treatment initiated if a patient's symptoms are moderate to severe [27]. Upon resolution of these symptoms, everolimus can be reinitiated at a reduced dose of $5 \mathrm{mg} /$ day. three oral agents can be used, initiation and intensification of insulin therapy is preferred based on effectiveness and lower expense. With kind permission from Springer Science Business Media: Diabetologia. Management of hyperglycaemia in type 2 diabetes mellitus: a consensus algorithm for the initiation and adjustment of therapy — update regarding the thiazolidinediones, 51:2008; 8-11, Nathan, DM, Buse, JB, Davidson MB, et al.; Fig. 1 (C) Springer-Verlag

The everolimus package insert also contains a clinical management strategy for the treatment of everolimus-related noninfectious pneumonitis (Table 3) [22].

\section{Infection}

Infection is a common AE reported in patients treated with everolimus (Table 1) [22,34]. The innate immunosuppressive properties of everolimus may predispose patients to bacterial, fungal, viral, or protozoal infections including pneumonia, sepsis, mycobacterial infections, aspergillosis, candidiasis, and reactivation of the hepatitis B virus. In the phase III RECORD-1 trial of everolimus (10 mg/day) in advanced RCC, everolimus-related severe infection was reported, including infection associated with fatal respiratory failure or sepsis. In BOLERO-2, sepsis caused two deaths [17]. Therefore, professionals should be vigilant in evaluating for signs and symptoms of infection with immediate appropriate treatment taken.

\section{Management recommendations}

In order to identify patients at greater risk for developing infection, a full medical history of prior infection should be obtained and laboratory tests conducted before commencing 
Table 3 Recommended clinical management strategy: noninfectious pneumonitis [22]

\begin{tabular}{|c|c|c|c|}
\hline Grade & Symptoms & Management & Everolimus dose modification \\
\hline 1 & Asymptomatic (radiographic findings only) & - Initiate appropriate monitoring & - No dose adjustment required \\
\hline 2 & Symptomatic, not interfering with ADLs & $\begin{array}{l}\text { - Rule out infection } \\
\text { - Consider treatment } \\
\text { with corticosteroids }\end{array}$ & $\begin{array}{l}\text { - Consider interruption of therapy until } \\
\text { symptoms improve to grade } \leq 1 \\
\text { - Reinitiate everolimus at a lower dose } \\
\text { - Discontinue treatment if failure to recover } \\
\text { within } 4 \text { weeks }\end{array}$ \\
\hline 3 & $\begin{array}{l}\text { Symptomatic, interfering with } \\
\text { ADLs; oxygen required }\end{array}$ & $\begin{array}{l}\text { - Rule out infection } \\
\text { - Consider treatment } \\
\text { with corticosteroids }\end{array}$ & $\begin{array}{l}\text { - Hold treatment until recovery to grade } \leq 1 \\
\text { - Consider reinitiating everolimus at a lower } \\
\text { dose. If toxicity recurs at grade } 3 \text {, consider } \\
\text { discontinuation }\end{array}$ \\
\hline 4 & Life threatening; ventilatory support indicated & & - Discontinue everolimus \\
\hline
\end{tabular}

$A D L$ activity of daily living

everolimus therapy including fungal, hepatitis, HIV, tuberculosis, and any other opportunistic infections or pulmonary conditions. Based on results from RECORD-1, a clinical management strategy has been outlined by an advisory panel for the treatment of grade 1 to 4 infection (Table 4). Patients with evidence of fungal infection should be comprehensively treated before everolimus initiation. If an invasive systemic fungal infection is suspected during treatment, everolimus should be immediately withdrawn and the patient treated with an appropriate antifungal $[27,45]$. For patients with hepatitis B virus infection, hepatitis B virus DNA should be monitored and antiviral prophylactic treatment given to prevent reactivation $[27,45]$. Current guidelines recommend the use of high-potency and high-genetic barrier agents to quickly suppress viremia while reducing progression of hepatic damage and the potential for developing resistant mutants [45].

\section{General adverse events observed in the BOLERO-2 study}

In addition to observing key AEs associated with mTOR inhibitors, other AEs were observed in $\geq 30 \%$ (mostly grade 1 and 2) or grade $3 / 4$ AEs reported in $\geq 3 \%$ of patients treated with everolimus combination therapy (Table 1) [17]. Most of these AEs are typically observed when treating cancer patients.

Fatigue

Cancer-related fatigue is defined as a distressing, persistent, and subjective sense of tiredness or exhaustion related to cancer or cancer treatment that is not proportional to recent activity and interferes with usual functioning [46]. In clinical trials, fatigue is frequently graded using the National Cancer Institute Common Toxicity Criteria [47], whereas in clinical practice, the ONS grades fatigue from 0 to 10 : with
0 being no fatigue and 10 representing the worst fatigue [48]. The ONS and National Comprehensive Cancer Network identifies exercise as a key intervention for preventing and treating cancer-related fatigue as supported by strong clinical evidence [48]. Other measures that are suggested to provide benefit in preventing and managing fatigue are nutrition consultation, energy conservation and sleep therapy, stimulus control therapy, strategies to reduce cognitiveemotional arousal, and progressive muscle relaxation training (e.g., relaxation breathing, yoga) $[46,48]$.

\section{Diarrhea}

Diarrhea is a common AE associated with cancer treatment. Nonpharmacologic and pharmacologic interventions can be used to control diarrhea and careful serial evaluation to rule out significant volume depletion or comorbidities that would require specific intervention or hospitalization $[49,50]$. Nonpharmacologic interventions include dietary modifications (ceasing the consumption of alcohol and of lactose-containing foods; eating frequent small meals) and aggressive oral rehydration with fluids that contain water, salt, and sugar [49,50]. Pharmacologic intervention typically includes loperamide. More severe cases may require hospitalization in order to provide more aggressive treatments $[49,50]$.

\section{Dyspnea}

Dyspnea is breathing discomfort of varying intensity or an uncomfortable sensation or awareness of breathing [51,52]. The causes of the condition in a patient with advanced cancer may be multifactorial and can be classified as indirect tumor effects (e.g., pneumonia, anemia) or direct tumor effects (e.g., primary/metastatic parenchymal lung involvement), treatment-related factors (e.g., radiation pneumonitis), or factors unrelated to cancer (e.g., comorbidities such 
Table 4 Recommended clinical management strategy: infections [22, 27]

\begin{tabular}{|c|c|c|c|}
\hline Grade & Description & Intervention & Everolimus dose adjustment \\
\hline 1 & None & $\begin{array}{l}\text { - Institute adequate treatment of infection } \\
\text { with antibiotics, as appropriate }\end{array}$ & $\begin{array}{l}\text { - If toxicity is tolerable, no dose adjustment } \\
\text { required }\end{array}$ \\
\hline & \multirow{5}{*}{$\begin{array}{l}\text { Localized infection, with local } \\
\text { intervention indicated }\end{array}$} & \multirow{2}{*}{$\begin{array}{l}\text { - Perform culture and be aware of } \\
\text { atypical infections }\end{array}$} & $\begin{array}{l}\text { - Initiate appropriate medical therapy and } \\
\text { monitor }\end{array}$ \\
\hline \multirow[t]{4}{*}{2} & & & $\begin{array}{l}\text { - If toxicity is tolerable, no dose adjustment } \\
\text { required }\end{array}$ \\
\hline & & \multirow{3}{*}{$\begin{array}{l}\text { - In patients who test positive for hepatitis } \\
\text { B surface antigen, consider prophylaxis } \\
\text { with entecavir or tenofovir }\end{array}$} & $\begin{array}{l}\text { - Initiate appropriate medical therapy and } \\
\text { monitor }\end{array}$ \\
\hline & & & $\begin{array}{l}\text { - If toxicity becomes intolerable, temporary } \\
\text { dose interruption until recovery to grade } \leq 1 \\
\text { Reinitiate everolimus at the same dose }\end{array}$ \\
\hline & & & $\begin{array}{l}\text { - If toxicity recurs at grade } 2 \text {, interrupt } \\
\text { everolimus until recovery to grade } \leq 1 \text {. } \\
\text { Reinitiate everolimus at a lower dose }\end{array}$ \\
\hline \multirow[t]{3}{*}{3} & \multirow{3}{*}{$\begin{array}{l}\text { IV antibiotic, antifungal, or antiviral } \\
\text { intervention indicated; interventional } \\
\text { radiology or surgery indicated }\end{array}$} & \multirow{3}{*}{$\begin{array}{l}\text { - Provide IV antibiotic, antifungal }{ }^{\mathrm{a}} \text {, or } \\
\text { antiviral therapy; institute additional } \\
\text { interventions as for grade } 1\end{array}$} & $\begin{array}{l}\text { - Temporary dose interruption until recovery } \\
\text { to grade } \leq 1\end{array}$ \\
\hline & & & $\begin{array}{l}\text { - Initiate appropriate medical therapy and } \\
\text { monitor }\end{array}$ \\
\hline & & & $\begin{array}{l}\text { - Consider reinitiating everolimus at a lower } \\
\text { dose. If toxicity recurs at grade } 3 \text {, consider } \\
\text { discontinuation }\end{array}$ \\
\hline 4 & $\begin{array}{l}\text { Life-threatening consequences such as } \\
\text { septic shock, hypotension, acidosis, } \\
\text { or necrosis }\end{array}$ & $\begin{array}{l}\text { - Provide appropriate standard } \\
\text { therapy, as for grade } 1\end{array}$ & - Discontinue everolimus \\
\hline
\end{tabular}

\section{$I V$ intravenous}

${ }^{a}$ If diagnosis of invasive systemic fungal infection is made, everolimus therapy should be promptly and permanently discontinued. Avoid coadministration of everolimus with strong cytochrome 3A4 inhibitors

as asthma, cardiac ischemia, or psychosocial pain). Pharmacologic agents may be considered and nonpharmacologic intervention methods include patient positioning (e.g., sitting upright in bed or in a chair), scheduling activities, keeping the room cool, having gentle air flow on the patient, promoting relaxation, and psychosocial support [53].

\section{Anemia}

Anemia, a deficiency in red blood cells (RBCs), frequently occurs among cancer patients, and has been shown to negatively impact survival and increase the risk of fatigue in patients [54]. The European Cancer Anaemia Survey defines anemia as hemoglobin levels $\leq 12 \mathrm{~g} / \mathrm{dL}$ [55], whereas the National Comprehensive Cancer Network guidelines define anemia as hemoglobin levels $\leq 11 \mathrm{~g} / \mathrm{dL}$, or $\leq 2 \mathrm{~g} / \mathrm{dL}$ below baseline [56]. Transfusions with packed RBCs can be a rapid and reliable method of treating anemia; however, such transfusions are associated with patient risks such as transfusion-related reactions, congestive heart failure, bacterial contamination, viral infections, and iron overload [56, 57]. An alternative strategy includes the use of erythropoiesisstimulating agent therapy. However, synthetic human recombinant human erythropoietin can stimulate erythropoiesis even in patients with low RBC levels. Hence, FDA has included a "black box" warning stating that erythropoiesis-stimulating agents should be used only to treat chemotherapy-induced anemia and discontinued once chemotherapy has been completed [56]. Iron supplementation is also generally required by most patients to ensure optimal erythropoiesis [58] and depending on iron status intravenous iron supplementation (low molecular weight iron dextran, ferric gluconate, or iron sucrose) administered if iron deficiency is suspected [56].

\section{Elevated transaminases}

Elevated transaminases is the general term used to describe elevation of aspartate aminotransferase (AST) and alanine aminotransferase (ALT) levels; elevations of less than five times the upper limit of normal are considered mild $[59,60]$. Hepatoxic medications and alcohol should be discontinued and any conditions that may cause elevated transaminase levels, such as diabetes, heart disease, and thyroid disease, identified and treated accordingly [59]. For patients with mild hepatic impairment (Child-Pugh class A), everolimus dose should be reduced to $7.5 \mathrm{mg}$ /day. For moderate hepatic impairment (Child-Pugh class B), everolimus dose should be reduced to $5 \mathrm{mg} /$ day [22]. In severely hepatic impaired 
patients (Child-Pugh class C), a dose of $2.5 \mathrm{mg}$ /day may be administered if the desired benefit outweighs the risk [22].

\section{Conclusions}

The oral mTOR inhibitor everolimus has demonstrated significant clinical efficacy in women with advanced HR-positive BC. In this patient population, everolimus is generally well tolerated, and treatment-related AEs are manageable with appropriate care. The critical and diverse roles of the health care provider should not be underestimated and include the responsibilities of patient education, early AE identification, pretreatment planning, monitoring during therapy, and effective treatment when AEs occur. AEs observed in patients with $\mathrm{BC}$ appear to be consistent with those in patients with RCC, for which everolimus is already approved and used routinely in the clinic. As the application of everolimus in the treatment of cancer expands, appropriate management of treatment-related AEs will be fundamental to improving patient quality of life and treatment outcomes.

Acknowledgments The author wishes to thank Clare Lee, PhD, Janardhan Sampath, PhD, Matthew Grzywacz, PhD, and ApotheCom (funded by Novartis Pharmaceuticals Corporation) for providing editorial and technical assistance in the development of this article.

Conflict of interest Mary Peterson participates in the Novartis Oncology Advisory Boards. Mary Peterson attests that she has had access to all data and agrees to permit the journal access to the data if requested.

Open Access This article is distributed under the terms of the Creative Commons Attribution Noncommercial License which permits any noncommercial use, distribution, and reproduction in any medium, provided the original author(s) and the source are credited.

\section{References}

1. American Cancer Society (2012) Cancer facts and figures 2012. American Cancer Society, Atlanta, pp 1-66

2. Harvey JM, Clark GM, Osborne CK, Allred DC (1999) Estrogen receptor status by immunohistochemistry is superior to the ligandbinding assay for predicting response to adjuvant endocrine therapy in breast cancer. J Clin Oncol 17:1474-1481

3. National Comprehensive Cancer Network, Inc (2012) NCCN Clinical Practice Guidelines in Oncology. Breast Cancer V1.2012

4. National Cancer Institute (2012) SEER Statistic Fact Sheet: Breast Cancer 2012

5. Mouridsen H, Gershanovich M, Sun Y et al (2003) Phase III study of letrozole versus tamoxifen as first-line therapy of advanced breast cancer in postmenopausal women: analysis of survival and update of efficacy from the International Letrozole Breast Cancer Group. J Clin Oncol 21:2101-2109

6. Johnston S, Pippen J Jr, Pivot X et al (2009) Lapatinib combined with letrozole versus letrozole and placebo as first-line therapy for postmenopausal hormone receptor-positive metastatic breast cancer. J Clin Oncol 27:5538-5546
7. Johnston SR (2010) New strategies in estrogen receptor-positive breast cancer. Clin Cancer Res 16:1979-1987

8. Yamashita H, Toyama T, Nishio M, Ando Y, Hamaguchi M, Zhang Z, Kobayashi S, Fujii Y, Iwase H (2006) p53 protein accumulation predicts resistance to endocrine therapy and decreased post-relapse survival in metastatic breast cancer. Breast Cancer Res $8: R 48$

9. Dodwell D, Wardley A, Johnston S (2006) Postmenopausal advanced breast cancer: options for therapy after tamoxifen and aromatase inhibitors. Breast 15:584-594

10. Hudes G, Carducci M, Tomczak P et al (2007) Temsirolimus, interferon alfa, or both for advanced renal-cell carcinoma. $\mathrm{N}$ Engl J Med 356:2271-2281

11. Motzer RJ, Escudier B, Oudard S et al (2010) Phase 3 trial of everolimus for metastatic renal cell carcinoma: final results and analysis of prognostic factors. Cancer 116:4256-4265

12. Hidalgo M, Buckner JC, Erlichman C, Pollack MS, Boni JP, Dukart G, Marshall B, Speicher L, Moore L, Rowinsky EK (2006) A phase I and pharmacokinetic study of temsirolimus (CCI-779) administered intravenously daily for 5 days every 2 weeks to patients with advanced cancer. Clin Cancer Res $12: 5755-5763$

13. Hess G, Herbrecht R, Romaguera J et al (2009) Phase III study to evaluate temsirolimus compared with investigator's choice therapy for the treatment of relapsed or refractory mantle cell lymphoma. J Clin Oncol 27:3822-3829

14. Yao JC, Shah MH, Ito T et al (2011) Everolimus for advanced pancreatic neuroendocrine tumors. N Engl J Med 364:514-523

15. Dancey JE, Monzon J (2011) Ridaforolimus: a promising drug in the treatment of soft-tissue sarcoma and other malignancies. Future Oncol 7:827-839

16. Chan S, Scheulen ME, Johnston S et al (2005) Phase II study of temsirolimus (CCI-779), a novel inhibitor of mTOR, in heavily pretreated patients with locally advanced or metastatic breast cancer. J Clin Oncol 23:5314-5322

17. Baselga J, Campone M, Piccart M et al (2012) Everolimus in postmenopausal hormone receptor-positive advanced breast cancer. N Engl J Med 366:520-529

18. Hortobagyi GN, Piccart M, Rugo H, et al. (2011) Everolimus for postmenopausal women with advanced breast cancer: Updated results of the BOLERO 2 Phase III trial. Presented at San Antonio Breast Cancer Symposium, San Antonio, December 8, 2011; S3-S7

19. Baselga J, Semiglazov V, van Dam P et al (2009) Phase II randomized study of neoadjuvant everolimus plus letrozole compared with placebo plus letrozole in patients with estrogen receptorpositive breast cancer. J Clin Oncol 27:2630-2637

20. Meric-Bernstam F, Gonzalez-Angulo AM (2009) Targeting the mTOR signaling network for cancer therapy. J Clin Oncol 27:2278-2287

21. Husseinzadeh HD, Garcia JA (2011) Therapeutic rationale for mTOR inhibition in advanced renal cell carcinoma. Curr Clin Pharmacol 6:214-221

22. Novartis Pharmaceuticals Corporation (2012) Afinitor (everolimus) tablets for oral administration. Novartis Pharmaceuticals Corporation, East Hanover, NJ

23. Novartis Pharma Stein AG (2010) Zortress (tablets for oral administration). Novartis Pharma Stein AG, Stein, Switzerland

24. Novartis (2012) Certican. Zuellig Pharma, Malaysia

25. Piccart M, Baselga J, Noguchi S, et al. (2012) Final progressionfree survival analysis of BOLERO-2: a phase III trial of everolimus for postmenopausal women with advanced breast cancer. Presented at: 2012 CTRC-AACR San Antonio Breast Cancer Symposium; San Antonio, December 4-8, 2012; P6-04-02

26. Wojtaszek C (2000) Management of chemotherapy-induced stomatitis. Clin J Oncol Nurs 4:263-270 
27. Porta C, Ostanto S, Ravaud A et al (2011) Management of adverse events associated with the use of everolimus in patients with advanced renal cell carcinoma. Eur J Cancer 47:1287-1298

28. Pilotte AP, Hohos MB, Polson KM, Huftalen TM, Treister N (2011) Managing stomatitis in patients treated with Mammalian target of rapamycin inhibitors. Clin J Oncol Nurs 15:E83-E89

29. Kostler WJ, Hejna M, Wenzel C, Zielinski CC (2001) Oral mucositis complicating chemotherapy and/or radiotherapy: options for prevention and treatment. CA Cancer J Clin 51:290-315

30. Eilers J (2004) Nursing interventions and supportive care for the prevention and treatment of oral mucositis associated with cancer treatment. Oncol Nurs Forum 31:13-23

31. Sonis S, Treister N, Chawla S, Demetri G, Haluska F (2010) Preliminary characterization of oral lesions associated with inhibitors of mammalian target of rapamycin in cancer patients. Cancer $116: 210-215$

32. Harris DJ, Eilers J, Harriman A, Cashavelly BJ, Maxwell C (2008) Putting evidence into practice: evidence-based interventions for the management of oral mucositis. Clin J Oncol Nurs 12:141-152

33. Flodin NW (1997) The metabolic roles, pharmacology, and toxicology of lysine. J Am Coll Nutr 16:7-21

34. Sankhala K, Mita A, Kelly K, Mahalingam D, Giles F, Mita M (2009) The emerging safety profile of mTOR inhibitors, a novel class of anticancer agents. Target Oncol 4:135-142

35. Balagula Y, Rosen A, Tan BH et al (2012) Clinical and histopathologic characteristics of rash in cancer patients treated with mammalian target of rapamycin inhibitors. Cancer 118:5078-5083

36. Fleishman SB, Fox LP, Garfield DH, Viele CS, Messner C (2012) Tips for managing treatment-related rash and dry skin. Cancer Care, New York, pp 1-20

37. American Diabetes Association (2012) Hyperglycemia and Diabetes, Available at: URL: http://www.medicinenet.com/ hyperglycemia/article.htm. Accessed February 7, 2012

38. Soefje SA, Karnad A, Brenner AJ (2011) Common toxicities of mammalian target of rapamycin inhibitors. Target Oncol 6:125-129

39. Grunwald V, Karakiewics PI, Bavbek SE et al (2012) An international expanded-access programme of everolimus: addressing safety and efficacy in patients with metastatic renal cell carcinoma who progress after initial vascular endothelial growth factor receptortyrosine kinase inhibitor therapy. Eur J Cancer 48:324-332

40. Nathan DM, Buse JB, Davidson MB, Ferrannini E, Holman RR, Sherwin R, Zinman B (2008) Management of hyperglycaemia in type 2 diabetes mellitus: a consensus algorithm for the initiation and adjustment of therapy: update regarding the thiazolidinediones. Diabetologia 51:8-11

41. Hollebecque A, Clamp A, Horsley L, Morgan JA, Bahleda R, George S, Shaw D, Lauchle JO, Ware J, Desai R, Wu J, Fu L, Jayson GC, Soria JC, Wagner AJ (2011) A phase I study evaluating the pharmacokinetics (PK) and pharmacodynamic (PD) activity of the dual PI3K/mTOR inhibitor GDC-0980 administered once weekly (QW). Presented at: AACR-NCI-EORTC International Conference: Molecular Targets and Cancer Therapeutics, November 12-16, 2011, San Francisco, CA
42. White DA, Camus P, Endo M et al (2010) Noninfectious pneumonitis after everolimus therapy for advanced renal cell carcinoma. Am J Respir Crit Care Med 182:396-403

43. Cho D, Signoretti S, Regan M, Mier JW, Atkins MB (2007) The role of mammalian target of rapamycin inhibitors in the treatment of advanced renal cancer. Clin Cancer Res 13:758s-763s

44. Duran I, Siu LL, Oza AM, Chung TB, Sturgeon J, Townsley CA, Pond GR, Seymour L, Niroumand M (2006) Characterisation of the lung toxicity of the cell cycle inhibitor temsirolimus. Eur J Cancer 42:1875-1880

45. European Association for the Study of the Liver (2012) EASL Clinical Practice Guidelines: management of chronic hepatitis B virus infection. J Hepatol 57:167-185

46. National Comprehensive Cancer Network, Inc. (2012). NCCN Clinical Practice Guidelines in Oncology. Cancer-Related Fatigue V1.2012)

47. National Institutes of Health (2009) Common terminology criteria for adverse events (CTCAE) Version 4.0. US Department of Health and Human Services, National Institutes of Health, National Cancer Institute, NIH Publication No. 03-5410

48. Eaton LH, Tipton JM (2009) Fatigue. In: Eaton LH, Tipton JM (eds) Putting evidence into practice: improving oncology patients outcomes. Oncology Nursing Society, Pittsburgh, pp 1-324

49. Benson AB III, Ajani JA, Catalano RB et al (2004) Recommended guidelines for the treatment of cancer treatment-induced diarrhea. J Clin Oncol 22:2918-2926

50. Stein A, Voigt W, Jordan K (2010) Chemotherapy-induced diarrhea: pathophysiology, frequency, and guideline-based management. Ther Adv Med Oncol 2:51-63

51. Dudgeon DJ (2002) Managing dyspnea and cough. Hematol Oncol Clin North Am 16:557-577

52. Ripamonti C (1999) Management of dyspnea in advanced cancer patients. Support Care Cancer 7:233-243

53. Glorieux P, Marion P (2009) Management of dyspnea in advanced cancer patients. BJMO 3:101-105

54. Bohlius J, Weingart O, Trelle S, Engert A (2006) Cancer-related anemia and recombinant human erythropoietin - an updated overview. Nat Clin Pract Oncol 3:152-164

55. Barrett-Lee P, Bokemeyer C, Gascon P, Nortier JW, Schneider M, Schrijvers D, Van Belle S (2005) Management of cancer-related anemia in patients with breast or gynecologic cancer: new insights based on results from the European Cancer Anemia Survey. Oncologist 10:743-757

56. National Comprehensive Cancer Network, Inc (2012) NCCN Clinical Practice Guidelines in Oncology. Cancer and ChemotherapyInduced Anemia V1.2012, pp 1-40

57. Spivak JL, Gascon P, Ludwig H (2009) Anemia management in oncology and hematology. Oncologist 14(suppl 1):43-56

58. Henry DH (1998) Supplemental iron: a key to optimizing the response of cancer-related anemia to rHuEPO? Oncologist 3:275-278

59. Giboney PT (2005) Mildly elevated liver transaminase levels in the asymptomatic patient. Am Fam Physician 71:1105-1110

60. American Gastroenterological Association (2002) Medical position statement: evaluation of liver chemistry tests. Gastroenterology $123: 1364-1366$ 